\title{
El videojuego de temática histórica como arte visual: anacronías conscientes y licencias creativas en la representación de espacios urbanos de la saga Assassin's Creed*
}

Recibido: 23/05/2019 | Revisado: 07/01/2020 | Aceptado: 03/03/2020

DOI: 10.17230/co-herencia.17.33.2

\author{
José Enrique Ocaña Romero** \\ joseenriqueor1987@gmail.com
}

\section{Francisco Javier Ruiz del Olmo*** \\ fjruiz@uma.es}

Resumen A partir de la revisión de bibliografía especializada y del análisis crítico-constructivo del trabajo de Dow (2013) que examina los anacronismos existentes en la recreación digital de la ciudad de Florencia en el videojuego Assassin's Creed II (2009), el presente trabajo explora la capacidad que tienen este tipo de videojuegos para reconstruir la ambientación de un período histórico concreto a partir del uso de anacronismos derivados de licencias creativas y de las necesidades artísticas propias del videojuego. Los resultados demuestran que el anacronismo es una herramienta que los desarrolladores de videojuegos históricos utilizan de forma intencionada para transmitir una imagen del pasado que resulte vigente y atractiva en la actualidad. Igualmente se evidencia la necesidad de una metodología propia dentro de los denominados Game Studies que aborde el videojuego como objeto de estudio artístico lejos del enfoque de líneas de investigación como los Historical Game Studies y otras disciplinas humanísticas.

\section{Palabras clave:}

Videojuegos, arte, Game Studies, Historical Game Studies, anacronismo, Assassin's Creed, simulación digital.
* Este artículo hace parte de la investigación realizada en el marco del doctorado en Comunicación Audiovisual de la Universidad de Málaga.

** Magíster en Desarrollos Sociales de la Cultura Artística de la Universidad de Málaga, España. ORCID: 0000-00020934-8981

**** Profesor Titular de la Universidad de Málaga, España. ORCID: 0000-0002-1953-1798 


\title{
Historically Themed Videogames as Visual \\ Art: Conscious Anachronism and Creative \\ Licenses in the Representation of Urban Spaces in the Assassin's Creed Series
}

\begin{abstract}
From the revision of specialized bibliography and the critical-constructive analysis of Dow's work (2013), which studies the existing anachronisms in the digital recreation of the city of Florence in the videogame Assassin's Creed II (2009), this study explores the capacity that these types of videogames have to rebuild the setting of a specific historic period from the use of anachronisms that arise from the creative licenses and the artistic needs that are typical of videogames. The results show that the anachronism is a tool that historical videogame developers use in a deliberate way to transmit an image from the past that seems current and attractive for the present. We observed the need to develop our own methodology within the area of game studies to tackle videogames as an artistic object of study, such that it is different from research areas such as historical game studies and other humanistic disciplines.
\end{abstract}

\section{Keywords:}

Videogames, art, game studies, historical game studies, anachronism, Assassin's Creed, digital simulation.

A lo largo de poco más de medio siglo, los videojuegos han pasado de ser vistos como un simple entretenimiento a ser considerados por numerosos investigadores como un producto de enorme trascendencia cultural y también artística. Así, se "hace necesaria la labor de curadores de contenido, historiadores y académicos que estudien las repercusiones" de este medio digital (González y Matas, 2017, p. 17), y son numerosas las investigaciones, sobre todo en el ámbito anglosajón, que indagan en el videojuego desde el prisma de la pedagogía, la psicología, la antropología, la sociología o la historia. Las investigaciones que abordan al videojuego desde estas disciplinas son de temática muy variada y tratan de forma recurrente, entre otras muchas cuestiones, la violencia, el impacto emocional o el valor pedagógico del videojuego.

También, aunque con menos frecuencia, salen a la luz estudios que relacionan arte y videojuegos, con enfoques tan diversos como las opiniones que existen sobre su artisticidad. Por ello, hay que dejar claro que esta investigación no pretende postularse al respecto, sino 
que el interés de este trabajo se fundamenta en establecer unas bases que permitan entender los mecanismos artísticos de estas obras y su relación con los estudios culturales.

La universidad española ha ignorado ( $y$, por lo general, sigue ignorando) las particularidades del videojuego, su impacto social y cultural y su carácter autónomo de otras disciplinas como la comunicación o la informática. En este sentido, la investigación española sobre los videojuegos [...] es esporádica y dispersa (Planells de la Maza, 2013, p. 525).

Sin embargo, el videojuego ya se encuentra en algunos de los museos más importantes del mundo ${ }^{1}$ y es motivo de inspiración y reflexión dialéctica para muchísimos artistas, aunque previamente ha tenido que atravesar un arduo camino para ser reconocido como elemento vehicular del arte:

Cada vez que una nueva tecnología proporciona un medio fresco en el mundo del arte, se encuentra con faltas de respeto, indiferencia o indignación y debe pasar por un período de aceptación [...]; predecesores del videojuego en este proceso de asimilación son la fotografía, el videoarte o el cine (Martin, 2007, p. 201). ${ }^{2}$

Para dejar más patente aún esta multiplicidad de opiniones al respecto de la artisticidad del medio, Hideo Kojima, uno de los padres del videojuego moderno y artífice de la popular serie Metal Gear (1987-2015), afirma que "un videojuego debería asegurarse de que las cien personas que juegan con él disfruten. Es como una especie de servicio. No es arte. Pero creo que la forma de ofrecer el servicio con un videojuego es un estilo artístico, un tipo de arte" (Isern, 2012, p. 2).

Por otra parte, Tavinor (2009) dice que "debemos distinguir entre las diversas artes que se encuentran en la realización de los videojuegos y la idea de que son arte en sí mismos" (p. 172). Es decir, en la creación de un videojuego asistimos a la conjunción de varias disciplinas como el dibujo, la música, la literatura o la escultura digital, pero otra cuestión muy distinta es afirmar que un videojuego concreto es una obra de arte. Martin (2007) intenta explicarlo

1 En 2013 se inauguró una exposición de videojuegos en el MoMA de Nueva York con una selección de catorce juegos, entre ellos Pac-man (1980), Tetris (1984) y flOw (2006), de una lista que se iría engrosando posteriormente.

2 Las traducciones de los textos en inglés son nuestras. 
haciendo un paralelismo con el cine: "La mayoría del público ve el cine como una forma de arte, pero no todas las películas son obras maestras" (p. 204). Esta situación descrita por Martin conlleva entrar en juicios de valor estético, pero es una afirmación que bien puede extenderse a los videojuegos dentro de la subjetividad tanto del creador como del usuario de este tipo de obras.

\section{Objetivos, hipótesis, metodología y problemática de la investigación}

Lo que se propone en este trabajo es una reflexión crítica hacia los argumentos usados por un historiador del arte que analiza el videojuego desde el rigor histórico y, por consecuencia, su valor como instrumento pedagógico. Nos referimos singularmente a Douglas N. Dow (2013) que, con su ya célebre y renombrado texto sobre el estudio del anacronismo en los espacios urbanos representados en el videojuego Assassin's Creed II (2009, en adelante ACII), pretende advertir de la peligrosidad que estas incongruencias temporales pueden tener para la percepción de los jugadores sobre los acontecimientos históricos y las ciudades y edificios emblemáticos que aparecen en el juego.

Partiendo de la idea de que debido al uso intencionado del anacronismo en la recreación de espacios urbanos y edificios en la saga de videojuegos Assassin's Creed (en adelante AC) por parte de los desarrolladores se consigue transmitir o comunicar una imagen del pasado que resulta vigente en la actualidad, se desarrollan los siguientes objetivos:

- Investigar el origen de los denominados Historical Game Studies (en adelante HGS) a partir de una breve descripción de la ludología y la narratología como antecedentes de los Game Studies.

- Analizarde forma crítica el artículo "Historical Veneers: Anachronism, Simulation, and Art History in Assassin's Creed II" de Dow (2013).

- Identificar anacronismos ejemplares en algunos títulos de la saga $\mathrm{AC}$, con especial empeño en las recreaciones virtuales de edificios emblemáticos y espacios urbanos, para analizar las causas y consecuencias de los mismos desde una perspectiva artística en concordancia con los argumentos desarrollados. 
- Comprobar si es necesaria una aplicación metodológica singular para el videojuego como objeto de estudio artístico, fuera del enfoque de los HGS.

Para llevar a cabo de manera efectiva la investigación, se parte de una metodología de análisis de contenido crítico de la revisión de la literatura existente. Se plantea principalmente un análisis de los trabajos y testimonios de algunos de los autores más relevantes en esta temática, así como el estudio de una selección de ejemplos paradigmáticos de anacronismos presentes en algunos títulos de la popular saga de videojuegos de corte histórico AC. La mayoría de los anacronismos señalados en el trabajo se limitan a los espacios y edificios históricos recreados en esta saga haciendo especial mención a ACII y a su versión digital del Renacimiento italiano presentando una de las recreaciones más logradas de la ciudad de Florencia.

Se manejan esencialmente dos elementos que dan cuerpo al sentido de la investigación. Por un lado, se aborda el análisis crítico del artículo de Dow (2013) sobre los anacronismos en ACII, se extrae la información y se reformula de manera descriptiva. Por otro, se toma a dicho videojuego como caso ejemplar de entre todos los de la serie para señalar algunos de los anacronismos más relevantes de la ciudad virtual de Florencia representada en dicho título. Otro de los aspectos a destacar y que han influenciado en el enfoque metodológico y en el desarrollo de la investigación es que los autores han jugado en profundidad a ACII. También se ha viajado a la ciudad de Florencia en 2018 y 2019, recorrido sus calles y tomado fotografías de sus edificios más emblemáticos, lo que, sin duda, ha ayudado enormemente a tomar un posicionamiento más crítico y empírico frente a los argumentos que Dow vierte en su investigación.

El enfoque artístico siempre estuvo presente en nuestra investigación y eso mismo nos llevó a cambiar en gran parte el sentido de esta. Originalmente la intención era realizar un análisis de contenido del videojuego ACII, haciendo énfasis en la recreación digital de Florencia y en la identificación de los anacronismos presentes en la ciudad y sus edificios más emblemáticos para establecer así una crítica comparativa con el artículo de Dow (2013). El objetivo inicial de analizar la calidad artística de la representación digital de la ciudad de Florencia se transformó en la intención de 
realizar una crítica a los HGS como metodología de estudio del videojuego resaltando de esta manera las carencias de esta línea de investigación, para así llamar la atención sobre la emergencia de un método que abordara al videojuego como objeto de estudio artístico.

\section{Conflictos teóricos: ludología, narratología y Game Studies}

Desde sus orígenes, los videojuegos siempre han estado estrechamente ligados al diseño y a la creación artística. Aunque los primeros desarrolladores no eran conscientes de la relación entre el arte y los videojuegos, estos "pueden ser considerados como una nueva forma de expresión artística en las últimas décadas, pero al igual que ocurre con las expresiones artísticas contemporáneas, la sociedad todavía no es capaz de asimilarlas y de hacerlas suyas" (Belli y López, 2008, p. 161).

Pong, el primer lanzamiento comercial publicado por la compañía Atari en noviembre de 1972, supuso una gran revolución en el ocio digital. Poco más tarde, personajes como Pac-man (1980) o Mario Bros $(1983)^{3}$ pasaron a formar parte de la cultura popular gracias, en gran medida, a su diseño artístico: sus formas, sus colores o sus sonidos.

Con los rápidos avances tecnológicos en el campo de las consolas domésticas, el videojuego ganó en complejidad y en profundidad artística absorbiendo poco a poco el lenguaje representativo de otras artes como el cine o la fotografía. Es por ello por lo que "una vez superada la sorpresa de su novedoso elemento interactivo, se vieron inmediatamente en la necesidad de arroparse con argumentos" (Villalobos, 2015, p. 89). En este contexto, van apareciendo trabajos que toman como referencia central al videojuego desde el ámbito de los estudios culturales: los Game Studies, herederos a su vez de los estudios sobre artes visuales y de la resolución de un conflicto entre los primeros teóricos del juego y del videojuego:

3 El personaje de Mario apareció por primera vez en el Donkey Kong de 1981. Dos años después sale como héroe principal en el videojuego Mario Bros acompañado de su hermano Luigi. 
Antes de 1982 la única teoría que existía radicaba en la práctica de los diseñadores de videojuegos, que innovaban y que con cada diseño contribuían a desarrollar el medio. Programadores como Warren Robinett (autor del revolucionario Adventure de 1979 para la Atari 2600) se sentían inseguros de sus métodos, incluso si sólo articulaban en el código de programación en lugar de hacerlo por escrito. Pero en 1982 Chris Crawford escribió The Art of Computer Game Design, el primer libro dedicado a la teoría del videojuego [...] que se preguntaba qué eran los juegos y porqué jugaba la gente, y a continuación sugería unas reglas de diseño, describiendo métodos y técnicas y defendiendo siempre el videojuego como una forma de arte (Wolf y Perron, 2003, p. 5).

A mediados de los 90 el videojuego se empezaba a consolidar como una forma de "narrativa transmedia" (término que fue acuñado por Henry Jenkins) ${ }^{4}$ gracias a las primeras adaptaciones al cine como Super Mario Bros (1993) o Street Fighter (1994) lo que, de cierta manera, ayudó al videojuego a ser reivindicado como objeto de estudio cultural dentro del ámbito académico por algunos investigadores pioneros. "No obstante, tuvo que pasar bastante tiempo hasta que los científicos vieran en ellos un referente cultural y social que justificara gran parte de las investigaciones futuras" (Planells de la Maza, 2013, p. 521).

La transición de lo analógico a lo digital a mediados de los 90 y la aparición de la World Wide Web trajeron consigo un nuevo concepto de estudio dentro del campo de los videojuegos: el hipertexto "como modelo idílico de narrativa no lineal" (Planells de la Maza, 2013, p. 521). El estudio del hipertexto y de lo multimedia evolucionó gracias al teórico nórdico Espen Aarseth ${ }^{5}$ y su obra Cybertext: Perpectives on Ergodic Literature (1997). Para Aarseth, los videojuegos superan la estructura de un hipertexto para constituirse en cibertextos: sistemas performativos ergódicos cercanos a la lógica configurativa. El concepto de ergódico se asienta sobre la idea de que un videojuego no se basa en seguir rutas lineales y eventos prediseñados, sino que el jugador debe hacer un esfuerzo extra para crear nuevos textos a partir del sistema subyacente. Algunos videojuegos que llevan a extremo

4 Henry Jenkins es un célebre académico estadounidense que ha aportado numerosas investigaciones sobre el fenómeno fan, la cultura participativa y los principios de la narrativa transmedia.

5 Aarseth fundó la revista digital Game Studies en 2001 (www.gamestudies.org). 
esta idea son sin duda los de la popular saga Souls (2009-2016) de la compañía nipona From software ya que, para entender su trama, el jugador debe ir investigando e interpretando los acontecimientos a medida que avanza en el juego, ya sea recogiendo documentos en los que se explican sucesos o dialogando con los NPC. ${ }^{6}$

Por otro lado, la teórica Janet Murray "concibió el videojuego como un nuevo medio capaz de contar historias desde una perspectiva dramática particular" (Planells de la Maza, 2013, p. 522). Murray se centró en el estudio de las propiedades narrativas del videojuego mientras que Aarseth defendía que debía ser analizado desde sus propias particularidades y que es "antes que cualquier otra cosa, un juego y un objeto interactivo" (Aarseth, 2004, p. 4549). Las aportaciones de ludólogos y narratólogos no solo abrieron nuevas líneas de investigación, sino que configuraron lo que hoy se conoce como Game Studies, "una disciplina de consenso que intenta dar cabida a toda perspectiva científica centrada en el fenómeno del juego" (Planells de la Maza, 2013, p. 522).

Planells de la Maza (2013) llama la atención sobre la necesidad de los Game Studies como disciplina para estudiar las particularidades del videojuego. De este campo, han emergido interesantes propuestas y marcos teóricos multidisciplinares para analizar "el fenómeno del videojuego, contemporáneo" (p. 523).

Surgen así los HGS, una línea de investigación emergente que empieza su andadura en 2007 en la revista Rethinking History. The Journal of Theory and Practice, la cual va dando cabida a los trabajos "sobre la Historia en formato lúdico, llegando en 2016 a publicar un número especial, Challenge the Past, dedicado exclusivamente a esta tendencia” (Peñate, 2017, p. 388). La mayoría de los autores que han aportado investigaciones en esta disciplina coinciden en señalar a "William Uricchio como el padre de los historical game studies" (Peñate, 2017, p. 389).

Mediante un breve artículo titulado "Simulation, history, and computer games", publicado en el libro de factura colectiva Handbook of Computer Game Studies de 2005, Uricchio marcó "la hoja de ruta

6 Del inglés non-player-character, hace referencia a los personajes no controlables que se encuentran en un videojuego. 
de los historical game studies y sus principales ejes de estudio" (Peñate, 2017, p. 389). Aunque después de este artículo el autor se desligaría completamente de este campo de estudio, dejó claro que le "gustaría explorar la relación de los juegos de computadora con los largos procesos culturales de comprensión histórica, concretamente con los debates disciplinarios dentro de la profesión histórica" (Uricchio, 2005, p. 327).

Entre estas primeras publicaciones y Challenge the Past de 2016, se publicó en 2014 el volumen colectivo Early Modernity and Video Games, el cual se divide en dos partes: una teórica y otra práctica en la que, esencialmente, se analizan aspectos históricos de la saga AC y "trata de averiguar cómo los videojuegos interactúan con la historia, usan la historia, y construyen historicidad" (Winnerling \& Kerschbaumer, 2014, p. 20).

Tan solo un año antes, en 2013, se publicó Playing with the Past, una obra "centrada en el estudio de las simulaciones digitales del pasado, que ha sido considerada el segundo hito en la trayectoria de los historical game studies" (Peñate, 2017, p. 391). La mayoría de las investigaciones publicadas en este volumen se acercan al videojuego histórico para señalar la calidad de las ciudades digitalmente simuladas, así como diferentes aspectos históricos, un patrón que se repite en muchas de las investigaciones que comparten este marco teórico. Planells de la Maza (2013) se plantea si “ipodemos tratar estas piezas lúdicas como un medio más o es necesario reflexionar y encauzar sus particularidades en un marco teórico propio?” (p. 523). En este punto de la investigación surgen algunas de las cuestiones principales a abordar con respecto a la cuestión anterior y al enfoque que ofrecen los HGS: ¿es más relevante analizar la fidelidad o el rigor histórico de la obra que profundizar en su carácter de obra de arte como tal? ¿Se podría tender un puente entre los HGS y el estudio del videojuego histórico como obra de arte en sí misma? 


\section{Simulaciones y simulacros en la saga Assassin's Creed}

"La historia es nuestro patio de juegos": bajo este eslogan, lafranquicia de videojuegos de corte histórico $A C$, 7 producida y desarrollada por Ubisoft, ha conseguido llamar la atención de los investigadores. Esta saga de videojuegos no supone un caso aislado ya que nuestro pasado histórico siempre ha servido como telón de fondo para contar historias y "crear narraciones en ricos mundos ludoficcionales" (Planells de la Maza, 2015, p. 16). De acuerdo con Peñate (2017), "autores como Adrienne Shaw, Douglas N. Dow y Emil Lundedal Hammar se han aproximado a su estudio desde distintas perspectivas [.. .] todos ellos sin abandonar la disciplina de la Historia" (p. 388).

En primer lugar, se observa que los videojuegos históricos han ido generando todo tipo de escenarios imaginarios dotados de mayor credibilidad y autenticidad según iban progresando la tecnología y la calidad gráfica de los equipos informáticos. En los últimos años, la recreación de acontecimientos históricos y su consiguiente conversión en espacios jugables se ha convertido en una tendencia muy atractiva para los usuarios de videojuegos. "Sólo en 2016, cinco de los treinta productos más populares trataban explícitamente acontecimientos y procesos del pasado o hacían referencia a ellos" (Peñate, 2017, p. 388), aunque existen numerosos precedentes. Títulos como Street Fighter (1987) o Final Fight (1989), ambos del género de lucha, ya mostraban esta pretensión desde hace décadas con el diseño de escenarios estáticos 2D inspirados en ciudades célebres como Nueva York o Tokio. ${ }^{8}$

Sin embargo, es en los videojuegos de corte histórico donde la recreación, la simulación y la ambientación tienen mayor peso. ${ }^{9}$ No solo implica la representación de ciudades, sino también la aparición

7 En 2007 tuvo lugar el primer lanzamiento y en 2018 se publicó el último bajo el nombre de Assassin's Creed Odyssey ambientado en la antigua Grecia. La franquicia cuenta con un total de once entregas canónicas hasta la fecha y recientemente se ha filtrado que el próximo capítulo de la saga estará ambientado en la cultura vikinga.

8 Los espacios urbanos también se han utilizado como forma de juego en sí mismos, dando origen al género de construcción de ciudades. Ejemplos de ello son SimCity (1989) o Cities: Skilines (2015).

9 Véase el caso de los juegos de acción bélica de las sagas Call of Duty o Battlefield en los que se recrean batallas de la Primera y la Segunda Guerra Mundial con sus respectivas localizaciones históricas. 
de personajes y tramas inspirados en sucesos históricos. Es lo que ocurre en casi todas las entregas de AC, cuya historia principal presenta el eterno conflicto entre dos sectas secretas: los asesinos y los templarios. La saga introduce de manera ingeniosa fragmentos de historia real en la narrativa ficticia que va desarrollando, por medio de varios videojuegos y ambientaciones. A partir de esta premisa, la línea principal se divide en dos subtramas vinculadas entre sí: la historia del pasado y la del presente. "La manera de revivir el pasado es una tecnología denominada Animus [...] que permite acceder a los recuerdos de nuestros ancestros codificados en el ADN" (Esteban, 2017, pp. 102-103). ACII se desarrolla en el Renacimiento italiano a finales del Quatroccento. Controlando al antepasado del protagonista por medio del Animus, podemos recorrer una versión muy lograda de las ciudades de Florencia, Venecia, el pequeño municipio de Monteriggioni y parte de la Toscana.

Por otro lado, en 2013 Douglas N. Dow publica un artículo vital para los HGS titulado "Historical Veneers: Anachronism, Simulation, and Art History in Assassin's Creed II" que se recoge en el volumen Playing with the Past. Digital Games and the Simulation of History. En esta investigación, Dow cuenta cómo acometió el análisis de la ciudad de Florencia recreada en ACII cuando varios de sus alumnos afirmaron haber aprendido muchas cosas sobre el Renacimiento italiano con dicho videojuego. En su estudio, toma como referencia principal la teoría sobre simulación e hiperrealidad del sociólogo y filósofo francés Jean Baudrillard ${ }^{10}$ "para examinar cómo la inclusión de monumentos anacrónicos en el paisaje urbano de la Florencia del juego influye en la comprensión del jugador sobre el entorno construido de la ciudad tal como se ve hoy día" (Dow, 2013, p. 216).

Dow dedica gran parte de su artículo a estudiar en detalle los anacronismos presentes en la arquitectura de la Florencia digital, es decir, pone de manifiesto los "errores" en la recreación de algunos edificios y sus fachadas, y los posibles efectos negativos que esto puede tener en los jugadores:

10 En uno de sus ensayos fundamentales, Cultura y simulacro (1978), Baudrillard se centró en describir los conceptos de hiperrealidad y simulacro en base a los cuales se establece un modelo virtual que suplantaría a la realidad. Dow parte de esta idea para la concepción de su artículo. 
La versión del juego de Santa Croce [...] está decorada con una fachada que se asemeja a la que adorna la iglesia real en la actualidad. Esta fachada no se construyó hasta 1863, pero su presencia en el juego sugiere que es mucho más antigua (Dow, 2013, pp. 219-220).

Según la lógica de Baudrillard expuesta por Dow, "el guiar a Ezio"11 a través de Florencia [...] sumerge al jugador en una simulación de la ciudad y difumina la distinción entre lo real y lo representado" (Dow, 2013, p. 218). Sin embargo, para Dow, esto no se cumple, ya que "no es una recreación exacta (simulación) de la ciudad del siglo XV y debe verse como un simulacro" (2013, pp. 218-19), es decir, una falsa semejanza que "colorea" la percepción del jugador en "lo que Anette Barnes y Jonathan Barnes llamaron un anacronismo no obvio [...] una sutil mezcla de ficción que puede hacer que los observadores sean incapaces de distinguir entre la falsedad y la verdad" (p. 220).

La investigación de Dow sobre los anacronismos en la Florencia digital, así como los últimos trabajos sobre la calidad y rigurosidad histórica de la representación del Renacimiento y su ambientación en ACII abordan el análisis del videojuego interpretándolo desde disciplinas como la Historia, la Sociología, la Antropología o la Historia del Arte. La aparición y la implicación de los Game Studies ha sido beneficiosa para la aceptación del videojuego como objeto de estudio formal, pero, por otro lado, implica que estas líneas de trabajo dejen de lado la naturaleza intrínseca del videojuego como obra de arte creada con la misión de entretener bajo sus propias mecánicas y leyes artísticas:

Como campo de investigación multidisciplinar, la teoría del videojuego tiene que ser -por naturaleza- la síntesis de una amplia variedad de enfoques, pero al mismo tiempo tiene que centrarse en los aspectos exclusivos de los videojuegos [...] es precisamente la irreductibilidad del videojuego lo que lo ha hecho tan difícil de definir formalmente y lo que ha provocado el intenso debate sobre no sólo lo que debería ser, sino también sobre lo que es exactamente (Wolf y Perron, 2003, p. 16).

Dow deja entrever estas cuestiones al comentar que las réplicas de los edificios que aparecen en el videojuego "no son simplemente escenografías, ya que el jugador debe navegarlas para conseguir los objetivos del juego. De hecho, el paisaje urbano fue diseñado para

11 Protagonista en la trama del pasado de Assassin's Creed II. 
acomodar la mecánica de juego" (2013, p. 216). Con esta afirmación Dow pone de manifiesto, de forma intuitiva, que la importancia del lenguaje y los mecanismos del videojuego funcionan en su propio universo.

Llegados a este punto nos hacemos una pregunta clave: ¿cómo consiguen los videojuegos como ACII construir y transmitir una imagen del pasado que resulte a su vez vigente en la actualidad? La respuesta se encuentra en los aspectos que critica Dow en su artículo: los anacronismos.

\section{Resultados. Anacronismos intencionados y sensación de familiaridad: el lenguaje artístico de los videojuegos históricos.}

ACII es un caso de estudio muy peculiar ya que, aparte de ser un videojuego de una gran factura artística, contiene numerosas referencias a obras de arte existentes en la realidad (es metaarte):

En el entramado urbano de la Florencia de ACII nos encontraremos con una serie de establecimientos en los que podemos adquirir obras capitales del Renacimiento Italiano [...] entre los autores de estas piezas hay algunas de Piero della Francesca, Botticelli, Leonardo, Rafael y Tiziano, entre otros (Leiva, 2018, p. 5).

Si adquirimos estas obras dentro del juego, más tarde aparecerán expuestas junto con otros objetos coleccionables en la villa de Ezio, como si de un museo renacentista se tratara.

Desde la historia del arte se han hecho análisis comparando con los modelos reales todas las obras arquitectónicas, pictóricas y escultóricas que aparecen en la recreación renacentista de ACII. En este sentido, Leiva (2018) relaciona el arte con los videojuegos y la historia para dar paso a un recorrido por la Florencia digital intercalando explicaciones sobre hechos históricos con la forma en la que están recreados los edificios y las anacronías que existen en ellos. El objetivo de la investigación resulta correcto, pero parece no estar claramente definido dado que finalmente concluye resaltando la obviedad de que el videojuego debe ser catalogado como arte simplemente por el hecho de que ACII tiene numerosas referencias a la historia del arte, o al menos eso es lo que se infiere. Con todo, y a nuestro juicio, el trabajo aporta ideas interesantes que no desarrolla lo suficiente: 
Los productores y desarrolladores se toman licencias, pero su objetivo principal no es el de hacer una reconstrucción histórica fidedigna, sino el de crear una imagen de verosimilitud con la que podamos hacer una aproximación medianamente adecuada a las características principales del período histórico en cuestión (Leiva, 2018, p. 4).

Y efectivamente, al igual que ocurre con otras artes representacionales como el cine, los videojuegos de corte histórico actuales ofrecen un alto grado de inmersión gracias en parte al realismo de sus gráficos. El jugador que se dispone a jugar a títulos como ACII experimenta un acercamiento a la vida del período histórico representado por medio de la interacción con el personaje protagonista y el desarrollo de la trama. Asimismo, la inmersión que ofrezca un videojuego está relacionada directamente con el entretenimiento que es capaz de generar. A mayor inmersión, más entretenimiento experimenta el jugador. Brown y Cairns (2004) coinciden con otros muchos autores en que la inmersión propone al jugador, en el caso de los videojuegos, una sensación de alejamiento de lo real seguida de la aceptación de situaciones irreales que guardan una verosimilitud dentro de ese entorno no real. Según Armenteros y Fernández (2011), "el juego exige una mayor participación en el usuario y presuponemos que una de las claves de la inmersión se encuentra en la forma en la que el jugador interactúa con el juego" (p. 166).

Dow afirma al respecto que "a medida que las reproducciones se vuelven más sofisticadas e interactivas, es más probable que las experiencias sean mediadas (y medidas) a través de reproducciones y simulaciones" (Dow, 2013, p. 223). Partiendo de esta conjetura, el autor da por hecho que para algunos jugadores no familiarizados con los videojuegos genere decepción y confusión visitar Florencia y encontrarse con esos anacronismos después de haber jugado a ACII. Dow (2013) también indica que

La inclusión anacrónica de otros monumentos no construidos durante el período de tiempo del juego garantiza que una persona que primero experimentó los principales hitos de Florencia en la versión simulada de la ciudad en Assassin's Creed II los reconozca al visitar la ciudad al visitar la ciudad real (p. 222).

Pero, para muchos, esto puede suponer el catalizador perfecto para que los jugadores investiguen por su cuenta sobre los sucesos 
históricos reales del Renacimiento. Otros autores que teorizan sobre las capacidades pedagógicas del videojuego están de acuerdo en que "un curioso efecto colateral de la falta de fidelidad [...] por parte de la saga es la polémica y el debate que posteriormente genera en sus seguidores" (Iturriaga y Téllez, 2014, p. 147), incitándolos a la reflexión y al aprendizaje autónomo.

Dow revela que los anacronismos exponen a los jugadores a una visión falsa de los acontecimientos históricos, pero no tiene en cuenta que aun así también sería posible enseñar Historia por medio de este tipo de videojuegos. Esta es una postura defendida por otros historiadores que están a favor de usarlos como elemento educativo en sus aulas porque piensan que sus mecánicas, a pesar de los anacronismos, hacen más sencillo que un estudiante se pueda interesar en estos temas tan áridos para muchos. Baron (2010), por ejemplo, afirma que los videojuegos históricos como Call of Duty: World at War (2008) se apropian de material de archivo y eso tiene una carga y efectos en la percepción que de la Historia tiene el jugador:

Sostengo que las formas particulares en que se utiliza el material de archivo documental en este juego tienen un poderoso potencial para dar forma a la manera en que los usuarios experimentan y piensan sobre los acontecimientos pasados representados (p. 303).

Aun así, educar al usuario no es el objetivo de las compañías que desarrollan este tipo de videojuegos, aunque "la trama que se quiere narrar se entrelaza de la forma más perfecta posible con la parte verificada de la Historia" (Rodríguez, 2015, p. 4). Si se realiza una radiografía de la calidad lograda por los artistas e investigadores que trabajaron en el diseño de la Florencia virtual se llega a la conclusión de que el propósito de dicho montaje es ofrecer una trama que resulte atractiva y entretenida. Y para ello, antes de ser completamente fiel a la Historia, debe ser creíble dentro del universo del juego. A esto se suma que el trabajo intensivo de documentación realizado por los creativos no tiene por qué verse finalmente reflejado. Raphael Lacoste, director de arte en ACII, afirmó en una entrevista lo siguiente:

No tenemos ni fotografías ni referencias contemporáneas con las que empezar cuando comenzamos a concebir un proyecto. Para lograr nuestros objetivos, nos comprometemos en largos e intensos períodos de 
investigación empleando documentación histórica, mapas de la época, ilustraciones, cuadros, diarios de viaje, etc. También tenemos la suerte de poder viajar a las localizaciones para tener un sentido real de las vistas, los sonidos y olores de esas ciudades fascinantes (Venables, 2011, p. 5).

Según las propias conclusiones expuestas en el volumen Playing with the Past, el anacronismo ejecutado de forma consciente abre la puerta a la curiosidad del jugador y a una posterior discusión entre los usuarios. Rodríguez (2015), historiadora de profesión, expone en su blog sobre la saga $\mathrm{AC}$ que la mayoría de esos anacronismos son intencionados por parte del equipo de desarrollo del juego y no son debidos a una incompetencia ya que cuentan con el asesoramiento de un historiador.

La prueba de que esos anacronismos son conscientes la podemos encontrar dentro del propio juego: en la base de datos del Animus. Uno de los personajes principales de ACII es un historiador llamado Shaun. Su función es ir instruyendo al protagonista cada vez que pasa por un edificio o conoce a algún personaje histórico relevante, ofreciéndole una breve referencia informativa a modo de notificación en la interfaz, que se va almacenando en la base de datos del Animus. En las entradas que se van generando durante la partida, el personaje de Shaun va dando pequeñas pistas sobre acontecimientos históricos que no están incluidos en la simulación que está reviviendo el protagonista por medio de la máquina Animus.

En la mayoría de los casos, el arte conceptual creado para el juego también revela estos anacronismos conscientes. Por ejemplo, en Assassin's Creed III (2012) se muestra al personaje histórico Charles Lee sin la compañía de su célebre manada de perros pomerania, pero este detalle sí se encuentra recogido en la base de datos del Animus y en el trabajo de arte conceptual llevado a cabo durante el proceso de preproducción del videojuego. En la cuarta entrega de la saga se explica que la empresa encargada de fabricar el Animus selecciona los fragmentos de la memoria del protagonista para ofrecer a los espectadores/jugadores una aventura mucho más atractiva y espectacular. Esto, que puede parecer una explicación pobre, realmente hace referencia directa al lenguaje artificioso usado en la creación de este tipo de videojuegos haciendo patente que los 
creadores los conciben como un montaje que mezcla hábilmente la ficción con los datos reales.

En Assassin's Creed Unity (2014), entrega ambientada en la Revolución francesa, aparece una versión digital a escala 1:1 de Notre Dame muy fiel a la catedral original. Sin embargo, Caroline Miousse, la creativa que dio vida al edificio, afirmó en una entrevista para la revista digital The Verge que tuvo que tomarse algunas licencias en el diseño de Notre Dame; cuando terminó el primer modelado, los testers del juego propusieron que el edificio se veía muy extraño sin las agujas tan icónicas que Viollet-le-Duc le incorporó en la gran restauración que se llevó a cabo a finales del siglo XIX y, según la diseñadora, "la mayoría de la gente las imagina [las agujas] cuando piensan en el edificio, por lo que decidí incorporarlas a mi creación incluso si técnicamente no debían estar allî” (Webster, 2014, p. 10). Las vidrieras de la catedral, al estar protegidas por derechos de autor, no se pudieron reproducir en el juego, optando así por crear una versión personal lejanamente inspirada en las originales. Con ejemplos como este resulta patente que el desconocimiento de los desarrolladores no estuvo de por medio, sino más bien el imaginario actual.

Pero ¿por qué motivo la ciudad que aparece en ACII guarda más similitud con la Florencia que se puede visitar actualmente que con la versión del Renacimiento? Estos anacronismos se suceden continuamente en los videojuegos de esta saga y podemos afirmar que, si se analizan como herramientas propias del lenguaje del videojuego, ayudan a situar al jugador en una época histórica como el Renacimiento basándose en referencias arquitectónicas más actuales. Cuando contemplamos Il duomo de Florencia en el videojuego,

[r]esulta evidente que la mampostería de la fachada está incompleta. Aunque esto refleja el estado inacabado de la catedral en el Renacimiento, la fachada en construcción en Assassin's Creed II no se parece a la fachada parcial que estaba en la catedral en el siglo XV. En cambio, recuerda la estructura del siglo XIX que millones de turistas ven cuando visitan Florencia hoy (Dow, 2013, p. 220).

El diseño que los creativos eligieron para representar el aspecto que luce Florencia en el videojuego hace posible que los jugadores experimenten algo parecido a ser turistas atemporales ya que, aunque no se logre una simulación perfecta del período histórico, se 
consigue transmitir al jugador una imagen del pasado a partir de una apariencia más actualizada y estilizada de la ciudad y sus elementos.

De ahí surgen estos anacronismos y por esta razón la fachada de la catedral de Santa María del Fiore que aparece en el videojuego es más parecida a la actual que a la original renacentista. Cabe destacar también que en muchos casos los edificios recreados son de una antigüedad tal que la Historia se ha encargado de borrar cualquier registro sobre el aspecto que lucían originalmente, por lo que usar el anacronismo para darle un aspecto actual parece ser la solución más eficaz.

De esta manera, la sensación de familiaridad se ve reforzada ya que el jugador encuentra un alto grado de similitud en los edificios más icónicos y en las particularidades de la ciudad captadas en el videojuego. Dependiendo del grado de conocimientos que tenga el usuario, le pasarán más o menos inadvertidos esos anacronismos, esas falsas semejanzas que el equipo creativo del juego lleva a cabo para evocar "no la exactitud, sino la personalidad de la ciudad [...] a fin de alcanzar una mayor sensación de familiaridad de cara al espectador" (Rodríguez, 2015, p. 8).

Otro buen ejemplo sería la iglesia dominica Santa Maria Novella. Según Leiva (2018):

[E]s uno de los edificios que mejor se han recreado, destacando su portada, el cuerpo externo de las naves del templo y la torre campanario [...] No obstante, la plaza en la que se ubica no tiene ningún parecido con la realidad, y la estatua del Apolo del Belvedere que hay en el centro de esta no se [descubrirá] hasta 1498 (p. 9).

Por otro lado, "la inclusión de monumentos que no se habían construido durante el tiempo en el que se establece el juego representa otra desviación" (Dow, 2013, p. 219). Vemos ejemplos de esto en la inclusión en ACII del corredor de Vasari añadido al Ponte Vecchio más tarde o en la cúpula de la iglesia de San Lorenzo construida en el siglo XVII.

En ACII, el equipo de desarrollo se centró en recrear con solvencia los edificios emblemáticos respetando la línea del paisaje de la urbe. Sin embargo, como ocurre con la omisión del baptisterio de San Giovanni, los desarrolladores decidieron adaptar el perfil arquitectónico de Florencia a la jugabilidad creando así rutas para que la navegación por el espacio resultara más disfrutable. Ezio escala y trepa a cualquier edificio, sube a los tejados para escapar de 
sus enemigos, navega por el interior y por el exterior de las iglesias con ayuda de andamios, cuerdas y algunos elementos ornamentales que nunca estuvieron allí realmente, pero que son colocados para favorecer la experiencia y las mecánicas de juego. Casi todas las decisiones de los desarrolladores a la hora de omitir o cambiar los elementos de la ciudad son tomadas con base en la propia naturaleza artística del videojuego.

\section{Conclusiones}

Con el desarrollo de los objetivos planteados se evidencia la complejidad de la hipótesis inicial, verificándose solo en parte ya que, como se ha señalado en el ejemplo de las vidrieras de Notre Dame protegidas por derechos de autor, el anacronismo en el videojuego histórico no siempre tiene una razón de ser creativa sino que a menudo está motivada por el imaginario popular. Por otro lado, su uso proyecta sobre los jugadores una imagen actualizada del pasado de la ciudad reafirmando así que el proceso de creación de un videojuego histórico queda sujeto a una serie de variables que dependerán de múltiples factores artísticos: su coherencia narrativa, su atractivo visual o estética y su jugabilidad o gameplay.

A partir de las anteriores premisas se puede entender en mayor profundidad cómo y porqué los videojuegos de corte histórico son capaces de generar una imagen del pasado vigente en la actualidad. Estos anacronismos son parte del carácter representacional del videojuego ya que, en definitiva, son obras de ficción creadas por un equipo de artistas con el fin de atraer al usuario y entretenerlo. Los HGS dan cabida al videojuego en el ámbito académico de una forma sólida. Sin embargo, esta línea de investigación favorece un panorama en el que los historiadores analizan este tipo de obras desde un punto de vista en el que prima el rigor y la fidelidad del discurso histórico obviando, la mayoría de las veces, la naturaleza artística del videojuego y diseccionándolo según los intereses de las distintas disciplinas que abordan su estudio.

El videojuego, en definitiva, no es otra cosa que una obra audiovisual (e interactiva) que funciona como catalizador de las diferentes disciplinas artísticas que contiene en formato digital. 
Esto lo reivindica como "herramienta artística digital de lenguaje multidisciplinar" (Hidalgo, 2011, p. 341) ya que un videojuego puede contener técnicas derivadas del cine, la fotografía, el dibujo, la pintura, la literatura o la música.

Esta concepción se complica aún más cuando se observa que el propio término "Arte" relacionado a los videojuegos se ha convertido ya en un anacronismo lingüístico porque su uso implica relacionar un concepto del siglo XIX con una obra que ha alcanzado la madurez en el XXI a pesar de que los videojuegos siempre han "mirado hacia atrás".

Finalmente, y en un intento por abrir puertas a futuras investigaciones, ya no es novedoso relacionar arte y videojuegos puesto que su relación se remonta a los orígenes de estos últimos. Lo que sí es novedoso, además de urgente, es la búsqueda de una metodología propia que ayude al videojuego a asentarse como obra de arte visual e interactiva ofrecida en un soporte digital de posibilidades que se presentan infinitas y constantemente mutables. Una metodología que, desde los Game Studies, permita analizar a los videojuegos como obras de arte autónomas más allá de los postulados teóricos que lo vinculan a otras formas de representación 【

\section{Referencias}

Aarseth, E. (1997). Cybertext: Perpectives on Ergodic Literature. The Johns Hopkins University Press.

Aarseth, E. (2004). Genre Trouble: Narrativism and the art of simulation. En Wardrip-Fruin, N. y Harrigan, P. (Eds.), First Person: New media as story, performance and game (pp. 45-55). MIT Press.

Armenteros, M. y Fernández, M. (2011). Inmersión, presencia y "flow". Contratexto, (19), 165-177. https://bit.ly/2BT3hOD

Baron, J. (2010). Digital historicism: Archival footage, digital interface, and historiographic effects in Call of Duty: World at War. Eludamos. Journal for Computer Game Culture, 4(2), 303-314. https://www. eludamos.org/index.php/eludamos/article/view/vol4no2-12/191

Belli, S. y López, C. (2008). Breve historia de los videojuegos. Athenea Digital, (14), 159-179. https://doi.org/10.5565/rev/athenead/v0n14.570 
Brown, E. y Cairns, P. (2004). A grounded investigation of game immersion. CHI ACM Conference of Human Factors in Computing. ACM Press.

Dow, D. (2013). Historical Veneers: Anachronism, Simulation, and Art History in Assassin's Creed II. En M. Kapell y A. Elliot. (Eds.), Playing with the past. Digital Games and the simulation of History (pp. 215-231). Bloomsbury.

Esteban, G. (2017). La construcción de la narración y el héroe en el videojuego a través del estudio de la saga Assassin's Creed, desde una metodología de análisis audiovisual, tomando como referencia las estructuras clásicas del guion cinematográfico. (Tesis doctoral). Universidad de San Pablo CEU, Madrid. https://bit.ly/2BJqEKB

González, M. y Matas, D. (2017). De sombras y bestias: La travesía de Team Ico. Héroes de papel.

Hidalgo, X. (2011). Videojuegos. Un Arte para la Historia del Arte. (Tesis doctoral). Universidad de Granada. https://digibug.ugr.es/ handle/10481/21727

Isern Meix, J. (2012, marzo 11). Kojima opina que los videojuegos no son arte. MeriStation. https://bit.ly/3ijarpf

Iturriaga, B. y Téllez, A. (2014). Videojuegos y aprendizaje de la Historia: la saga Assassin's Creed. Contextos educativos, (17), 145-155. https://doi. org/10.18172/con.2598

Leiva Aldea, J. (2018). (Re) visitando la Florencia del Renacimiento. Revista Eviterna, (Especial 3), 1-12. https://doi.org/10.24310/Eviternare. v0i0.8223

Martin, B. (2007). Should videogames be viewed as art? En A. Clarke y G. Mitchell (Eds.), Videogames and Art (pp. 201- 209). Intellected Books.

Peñate, F. (2017). Los Historical Game Studies como línea de investigación emergente en las Humanidades. Cuadernos de Historia Contemporánea, (39), 387-398. http://dx.doi.org/10.5209/CHCO.56282

Planells de la Maza, A. (2013). La emergencia de los Game Studies como disciplina propia: investigando el videojuego desde las metodologías de la Comunicación. Historia y Comunicación Social, (18), 519-528. http://dx.doi.org/10.5209/rev_HICS.2013.v18.43985 
Planells de la Maza, A. (2015). Videojuegos y mundos de ficción. De Super Mario a Portal. Cátedra.

Rodríguez, I. (2015). El videojuego como vía de expresión cultural. Blog Licencia Histórica. https://bit.ly/38H3UXJ

Tavinor, G. (2009). The Art of Videogames. Wiley-Blackwell.

Uricchio, William. (2005). Simulation, history, and computer games en Handbook of Computer Game Studies. En J. Raessens y J. Goldstein (Eds.), Handbook of Computer Game Studies (pp. 327-339). MIT Press.

Venables, M. (2011, marzo 11). Exclusive Interview: Ubisoft's Creative Teams on Assassin's Creed Revelation. Wired. https://bit.ly/2CoBCov

Villalobos, J. (2015). Cine y Videojuegos. Un diálogo transversal. Héroes de papel.

Webster, A. (2014, abril 17). Building a better Paris in Assassin's Creed Unity. The Verge. https://bit.ly/2VY4XNC

Winnerling, T. y Kerschbaumer, F. (2014). Early Modernity and Video Games. Cambridge Scholar.

Wolf, M. y Perron, B. (2003). Introducción a la teoría del videojuego. Formats: Revista de Comunicación Audiovisual, (4), 1-27. https://bit. ly/2Obk024

\section{Videojuegos citados}

Activision (2003-2019). Call of duty [serie de videojuegos] [Multiplataforma]. Activision.

Activision (2008). Call of duty: World at War [videojuego] [Multiplataforma]. Activision.

Atari / Namco (1972). Pong [videojuego] [Arcade]. Atari.

Atari (1980). Adventure [videojuego] [Arcade]. Atari.

Atari (1980). Pac-Man [videojuego] [Arcade]. Atari / Namco.

Capcom (1987). Street Fighter [videojuego] [Arcade, Windows]. Capcom.

Capcom (1989). Final Fight [videojuego] [Arcade]. Capcom. 
Colossal Order (2015). Cities: Skylines [videojuego] [Multiplataforma]. Paradox Interactive.

Electronic Arts (2002-2018). Battlefield [serie de videojuegos] [Multiplataforma]. Electronic Arts.

From Software (2009-2016). Demon Souls y trilogía Dark Souls [serie de videojuegos] [Multiplataforma]. From Software.

Konami / Hideo Kojima (1987-2015). Metal Gear [serie de videojuegos] [Multiplataforma]. Konami / Hideo Kojima.

Nintendo (1983). Mario Bros [videojuego] [Arcade]. Nintendo.

Nintendo (1989). SimCity [videojuego] [SNES, móviles]. Nintendo.

Pázhitnov, A. (1984). Tetris [videojuego] [Multiplataforma]. Alekséi Pázhitnov.

Thatgamecompany (2006). Flow [videojuego] [PSP, Playstation 3, Playstation 4, PS Vita y Browser].

Ubisoft (2007). Assassin's Creed [videojuego] [Playstation 3, Xbox 360, Windows]. Ubisoft Montreal.

Ubisoft (2009). Assassin's Creed II [videojuego] [PlayStation 4, Xbox One, PlayStation 3, Xbox 360, Microsoft Windows, Mac OS]. Ubisoft Montreal.

Ubisoft (2012). Assassin's Creed III [videojuego] [PlayStation 4, Xbox One, PlayStation 3, Xbox 360, Wii U, Microsoft Windows]. Ubisoft Montreal.

Ubisoft (2014). Assassin's Creed Unity [videojuego] [PlayStation 4, Xbox One, Microsoft Windows]. Ubisoft Montreal.

Ubisoft (2018). Assassin's Creed Odyssey [videojuego] [PlayStation 4, Xbox One, Microsoft Windows]. Ubisoft Quebec. 